\title{
DIREITO À SAÚDE E UNIDADES DE TRATAMENTO INTENSIVO NEONATAL (UTINS): UMA BREVE REFLEXÃO SOBRE A EFICÁCIA DAS DECISÕES JUDICIAIS NO ESTADO DO MARANHÃO
}

RIGHT TO HEALTH AND NEONATAL INTENSIVE CARE UNIT (NICU): A BRIEF REFLECTION ON
THE EFFECTIVENESS OF JUDICIAL DECISIONS IN THE STATE OF MARANHÃO

Edith Maria Barbosa Ramos ${ }^{1}$ Lidia Cunha Schramm de Sousa ${ }^{2}$

Resumo: A judicialização das políticas públicas de saúde é um fenômeno crescente em todo o País, tendo diversos âmbitos do Poder Judiciário recebido demandas relacionadas à saúde, no entanto, percebe-se que essa discussão tem reflexos nos três Poderes. $O$ presente artigo teve por escopo compreender o sistema normativo que regulamenta o acesso a leitos de Unidades de Tratamento Intensivo Neonatal (UTINs), bem como analisar a eficácia das decisões judiciais no Maranhão, com foco nas decisões de magistrados da $1^{\text {a }}$ Vara da Infância e Juventude da comarca de São Luís, MA. Realizou-se um estudo descritivo e exploratório, com levantamento bibliográfico e documental, notadamente, em documentos disponibilizados nos sites do Poder Judiciário maranhense, do Ministério da Saúde, Secretaria de Saúde do Estado do Maranhão e do Município de São Luís. Ao fim, foram feitas algumas considerações sobre a problemática da judicialização da saúde como fenômeno que expõe as fragilidades e as descontinuidades das ações desenvolvidas pelas casas legislativas, pela gestão pública e pelo próprio sistema de justiça.

Palavras-chave: Direito à saúde. Unidade de tratamento intensivo. Poder Judiciário.

\begin{abstract}
The legalization of public health policies is a growing phenomenon throughout the country, having many areas of the Judiciary received demands related to health, however, it is clear that this discussion is reflected in the three Branches. This article had the scope to understand the legal system that regulates access to the Neonatal Intensive Care Unit beds (NICUs) and to analyze the effectiveness of judgments in Maranhão, focusing on judges decisions of the 1st Court of Childhood and Youth of the district of São Luís, MA. We conducted a descriptive study, with bibliographic and documental survey, notably in documents available on the websites of the judiciary of Maranhão, the Ministry of Health, Health Secretariat of the State of Maranhão, and the City of São Luís. In the end, some considerations were made about the problem of the judicialisation of health as a phenomenon that exposes the weakness and discontinuity of the actions developed by legislative bodies, public management and own justice system.
\end{abstract}

Keywords: Right to health. Neonatal Intensive Care Unit. Judicial Branch.

\footnotetext{
Pós-Doutora em Direito Sanitário pela Fundação Oswaldo Cruz; Doutora em Políticas Públicas pela Universidade Federal do Maranhão; Professora na Universidade Federal do Maranhão, Centro de Ciências Sociais; Avenida dos Portugueses, Campus Universitário do Bacanga, 65080-040, São Luís, Maranhão, Brasil; edithramosadv@yahoo.com.br

2 Mestre em Direito e Instituições de Sistema de Justiça pela Universidade Federal do Maranhão; Graduada em Direito pela Universidade Federal do Maranhão; Professora na Universidade Ceuma; edithramosadv@yahoo.com.br
} 


\section{Introdução}

O direito à saúde está assegurado na Constituição Federal, em seu artigo 196, como direito de todos e dever do Estado. O direito à saúde é, portanto, um direito público subjetivo tutelado constitucionalmente (DALLARI, 2013), devendo ser formulado e implementado pelo Poder Público por meio de políticas públicas sociais e econômicas (PINHEIRO; ASENSI, 2010) com o escopo de garantir o acesso universal e integral (RAMOS, 2014) à promoção, à proteção e à recuperação da saúde.

O direito à saúde é consequência lógica e indispensável do direito à vida (RAMOS, 2014), e em razão disso, o Poder Público, em todas as suas esferas institucionais (MACHADO, 2013), não pode se mostrar indiferente ao grave problema de saúde pública da população.

Verificou-se que, sobretudo após a promulgação da Constituição Federal de 1988, que a garantia do direito à saúde se tornou imperativo tanto da atuação do Poder Executivo (DALLARI, 2013), o qual deve implementar políticas públicas, quanto do Poder Judiciário, na salvaguarda dos diferentes interesses em saúde da população (VENTURA et al., 2010). Esse crescente do Poder Judiciário em situações que, em primeiro plano, são da competência do Poder Executivo (OLIVEIRA et al., 2015), é chamado de judicialização das políticas públicas.

O objetivo com o presente artigo foi analisar, a partir da problemática da judicialização das políticas públicas de saúde e suas consequências, as decisões judiciais na garantia da cobertura assistencial oferecida pelo Sistema Único de Saúde (SUS) em serviços de UTI neonatal públicos no Estado do Maranhão. Para tanto, foram analisadas as normas legais e infralegais que regulamentam a cobertura assistencial de leitos de UTI neonatal ofertados pelo SUS, bem como as ações judiciais relacionadas à temática da garantia de acesso aos leitos de UTI neonatal no Estado do Maranhão entre 2012 e 2013.

A necessidade de se discutir esse tema se calcou justamente no fato de que, via de regra, as políticas públicas de saúde não se apresentam como suficientes e efetivas (SARRETA, 2009) para suprirem as necessidades da população, em especial, de internação em leitos de unidades de tratamento intensivo neonatal da sociedade maranhense. Todos os dias pacientes com risco de morte, sobretudo os mais necessitados, ${ }^{3}$ procuram a rede pública hospitalar para internação e, não raro, são surpreendidos com a ausência de vagas. O resultado é a superlotação dos hospitais (BITTENCOURT; HORTALE, 2009) e a ineficiência das decisões judiciais.

A pesquisa demonstrou que um dos elementos obstaculizadores do cumprimento das decisões judicias no Estado do Maranhão, no período analisado, foi a falta de leitos em Unidade de Tratamento Intensivo (UTI), fato que demonstra claramente o descumprimento das bases normati-

3 Entende-se necessitado aquele que, de acordo com o inciso LXXIV, artigo $5^{\circ}$ da CF 1988, comprovar insuficiência de recursos. 
vas legais e infralegais do sistema legislativo da saúde. Observou-se, ainda, que a alta complexidade do serviço demanda vultosos investimentos e aporte de recursos (AMARAL, 2001), necessidades públicas descumpridas sob a justificativa da limitação orçamentária ou da reserva do possível. Desta feita, a especialidade neonatal acaba restrita a poucos hospitais. Na capital do Maranhão esse problema é maximizado diante da concentração da demanda em virtude da carência de rede hospitalar no interior do Estado.

Nesse cenário, percebeu-se um silêncio do Poder Executivo local no que diz respeito aos serviços de saúde de alta complexidade, fato verificado pela crescente solicitação do Poder Judiciário em relação a vagas em UTIs de hospitais particulares, diante do déficit nos hospitais da rede pública, constatação que demarca a gravidade do problema, considerando a seletividade econômica do acesso ao tratamento.

Realizou-se um estudo descritivo e exploratório, com levantamento bibliográfico, normativo e documental, notadamente, em documentos disponibilizados nos sites dos Ministérios da Saúde, Secretaria de Saúde do Estado do Maranhão e do Município de São Luís. Para a efetiva demonstração dessa realidade e abastecidos do suporte teórico necessário (AÑóN, 2009; RAMOS, 2014; OLIVEIRA et al., 2015) foi realizada uma busca processual com o Tribunal de Justiça do Maranhão de demandas que tiveram por objeto a solicitação de internação em leitos de Unidades de Tratamento Intensivo Neonatal (UTINs) no Estado do Maranhão, no período de 2012 a 2013.

Primeiramente, foi realizada uma análise quantitativa dos dados de UTINs públicas presentes no Estado do Maranhão (estaduais e municipais), bem como no Hospital Universitário Presidente Dutra, que embora de âmbito federal, realiza atendimento em convênio com o Município de São Luís, capital do Maranhão. Em seguida, foram identificados sete autos dos processos judiciais, fornecidos pelo Tribunal de Justiça do Maranhão, que continham pedido de UTINs.

$O$ presente artigo foi dividido em duas partes principais. A primeira tratou do conceito de acesso à saúde e sua normatização, bem como do panorama da prestação do serviço no Estado do Maranhão. Na segunda parte, abordou-se a Portaria n. 930/2012 do Ministério da Saúde e analisaram-se as demandas judiciais acessadas sobre UTINs no Estado pesquisado.

\section{Direito e garantia de acesso a serviços de saúde}

A palavra "usar", a título de conceito em âmbito sanitário, envolve todo contato direto, entre os quais, as consultas médicas, as hospitalizações e os diagnósticos; ou de forma indireta, quando se aborda o contexto da promoção e prevenção da saúde (ASSIS; JESUS, 2012). O que define o processo de utilização dos serviços de saúde é o intercâmbio da ação do indivíduo que busca cuidados e do profissional que o conduz no interior do sistema (MOIMAZ et al., 2010); via de regra, é o usuário quem faz o primeiro contato com os serviços de saúde, e, por sua vez, os profissionais de saúde tornam-se responsáveis pelos contatos ulteriores. São esses últimos, em maior medida, 
que definem o tipo e a amplitude de recursos consumidos para elucidar os problemas demandados (TRAVASSOS; MARTINS, 2004).

Para Travassos e Martins (2004), de modo geral, a utilização dos serviços de saúde é determinada pelos seguintes fatores: necessidades de saúde, usuários, prestadores de serviços, organização e política. A influência de cada um desses fatores varia de acordo com o tipo de serviço prestado e da própria proposta assistencial apresentada.

O conceito de acesso à saúde (AÑón, 2009) e a ideia-padrão de um modelo que possa medi-lo têm sido objeto de muita discussão, porém, sua definição, para Sanchez e Ciconelli (2012), tornou-se muito mais complexa por meio do agrupamento de aspectos de difícil mensuração. Acesso é uma palavra intricada ou imprecisa e obscura na sua relação com o uso de serviços em redes de saúde. A sua terminologia muda em razão da concepção pressuposta e do contexto em que está inserida e também possui variação no decorrer da história.

Donabedian (2002) utiliza a terminologia acessibilidade, definida como a atitude ou qualidade do que é acessível. Outros autores utilizam o substantivo acesso, considerado como ato de entrada, ingresso, ou ainda empregando as duas terminologias para apontar o grau de facilidade com que o indivíduo consegue cuidados de saúde. Existem, ainda, definições com outro enfoque: "uns centram-no nas características dos indivíduos; outros o focam nas características da oferta; alguns em ambas as características ou na relação entre os indivíduos e os serviços (oferta)." (TRAVASSOS; MARTINS, 2004). Além disso, Donabedian (2002) expõe que o termo acessibilidade como um dos aspectos da oferta de serviços correspondente à capacidade de garantir serviços de dar respostas às necessidades de saúde de um certo grupo populacional. $\bigcirc$ que o autor quis destacar foi que a acessibilidade tem conotação bem mais abrangente que mera disponibilidade de recursos em determinados espaço e tempo; isso tem a ver com o impacto que exercem na capacidade da população de usufruir do serviço, ou seja, representa uma dimensão fundamental nos estudos sobre equidade em saúde.

Muito embora seja ainda observada uma grande discussão na literatura sobre a definição de acesso à saúde, a maior parte dos autores aquiesce que acesso não se resume à simples utilização do serviço de saúde (RAMOS, 2014). "O acesso tem sido descrito como a oportunidade de utilização dos serviços em circunstâncias que permitam o uso apropriado dos mesmos." (SANCHEZ; CICONELLI, 2012). Deve-se considerar que a discussão de desigualdades em saúde traz à baila, fundamentalmente, a definição de equidade no cuidado com a saúde.

Para Rawls (2008), a equidade somente pode ter sua efetividade reconhecida a partir da pressuposição da posição original. Essa posição original deve ser explicada de modo que se possa, a qualquer momento, adotar a sua expectativa. "Deve ser indiferente a ocasião em que alguém adota esse ponto de vista, ou quem o faz: as restrições devem ser tais que os mesmos princípios são sempre escolhidos." (RAWLS, 2008, p. 149). Assim, o "véu da ignorância" torna-se fundamental na satisfação desse requisito. $\bigcirc$ autor garante não apenas que a informação disponível seja relevante, mas, sobretudo, que seja a mesma em todas as ocasiões. 
Na sequência, para que a posição original determine acordos justos, as partes necessitam estar colocadas de forma equitativa e devem ser tratadas de forma igual como pessoas éticas. "A arbitrariedade do mundo deve ser corrigida por um ajuste das circunstâncias da posição contratual inicial." (RAWLS, 2008, p. 152).

Dessa forma, observa-se que a teoria de justiça rawlsiana é de base contratualista, diferente de suas antecessoras pelo fato de o contrato original ter por escopo a instituição de princípios de justiça básicos da sociedade, enquanto que, nas teorias precedentes, o objeto do acordo original é a fundação de uma sociedade ou de um governo.

O local apropriado para a formação desse consenso (vale dizer, para a escolha dos princípios de justiça que se aplicarão à estrutura básica da sociedade) é a posição original, que representa uma situação inicial de igualdade, garantidora da equidade dos acordos fundamentais nela alcançados. Segundo Vita (2007, p. 182), a posição original é o "ponto arquimediano" da teoria de justiça de Rawls, significando que:

[... as oportunidades de vida e o bem-estar dos cidadãos de uma sociedade democrática não podem depender do acaso genético ou social, isto é, de uma loteria na distribuição de posições sociais, renda e riqueza, talentos naturais e mesmo concepções de bem; e que, portanto, as instituições básicas de tal sociedade devem ser concebidas para funcionar de forma que neutralizem tanto quanto possível a influência desses fatores - que via de regra encontram-se ou inteiramente ou em grande medida fora do alcance do controle individual - sobre a vida que cada pessoa é capaz de levar. Rawls sustenta que os fatores que respondem pelo acesso desigual a recursos sociais escassos são arbitrários de um ponto de vista moral. Esses fatores, por isso, não podem ter nenhum peso no acordo sobre os princípios de justiça que deverão vigorar em uma sociedade constituída por cidadãos livres e iguais.

E esses fatores arbitrários não desempenham qualquer papel na escolha dos princípios de justiça em razão de as partes do acordo estarem situadas por trás de um véu de ignorância, que impede os indivíduos de conhecerem o seu lugar na sociedade (posição e status social), a sua boa ou má sorte na distribuição de talentos e capacidades naturais, os seus fins últimos e interesses, a sua constituição psicológica particular e o atual estágio da sociedade - distribuição de recursos naturais e produtivos, bem como o nível de tecnologia (RAWLS, 2011, p. 323).

Para Rawls (2008), esse véu da ignorância garante que os princípios eleitos sejam justos, já que como os indivíduos desconhecem a sua situação na sociedade, ninguém proporá princípios que favoreçam injustamente uma posição social específica, de modo que os fatores contingenciais não influenciam a escolha dos princípios reguladores das relações sociais. Nessa situação inicial de igualdade, os princípios de justiça que serão escolhidos são os seguintes:

a. Cada pessoa deve ter um direito igual a um sistema plenamente adequado de liberdades fundamentais que seja compatível com um sistema similar de liberdades para todos.

b. As desigualdades sociais e econômicas devem satisfazer duas condições. A primeira é que devem estar vinculadas a cargos e posições abertos a todos, em condições de igualdade equitativa de oportunidades; a segunda é que devem redundar 
no maior benefício possível para os membros menos privilegiados da sociedade. (RAWLS, 2011, p. 345).

O primeiro princípio, que é prioritário sobre o segundo, significa que todos devem ter acesso a um sistema de liberdades e direitos fundamentais iguais, vale dizer: as normas definidoras dessas liberdades devem se aplicar igualmente a todos e permitir "a mais abrangente liberdade compatível com uma liberdade semelhante para todos." (RAWLS, 2008, p. 77).

Tais liberdades não podem ser violadas em nome da obtenção de maiores vantagens econômicas e sociais, somente podendo ser restringidas quando colidirem entre si. Por isso, vale dizer que o primeiro princípio de justiça de Rawls tem precedência sobre o segundo.

Rawls (2008) pretende tratar acerca de questões de justiça social relacionadas à estrutura básica da sociedade, que é a responsável pela distribuição dos bens primários sociais, definidos como as "coisas que todo indivíduo racional presumivelmente quer", na medida em que têm utilidade "sejam quais forem os planos racionais de vida da pessoa." (RAWLS, 2008, p. 75).

Esses bens primários são os direitos, as liberdades e as oportunidades, a renda e a riqueza, que, no arranjo hipotético imaginado pelo autor, são igualitariamente distribuídos, ressaltando-se que essa repartição igualitária não significa igualdade absoluta, uma vez que alguns podem receber mais bens primários se isso melhorar a situação dos que têm menos (RAWLS, 2008).

Ao lado desses bens primários sociais situam-se os chamados bens naturais, os quais, embora possam sofrer influência da estrutura básica da sociedade, não estão sob o seu controle direto. Rawls (2008) inclui entre os bens naturais a saúde, a inteligência e a imaginação. Segundo Mario (2014, p. 5),

[...] podemos entender a partir da formulação de Rawls que a saúde não é um bem que possa vir a ter impacto negativo sobre a vida das pessoas a ponto de sua ausência resultar em injustiças sociais e, por ser um bem primário natural, não seria passível de distribuição pela estrutura básica apesar de poder ser afetada por essa. Sob esse último aspecto, a manutenção da saúde seria muito mais responsabilidade do indivíduo do que das instituições da estrutura básica, pois, há de se considerar que renda, riqueza, oportunidades e liberdade já foram igualitariamente distribuídos.

Essa, no entanto, é a ideia defendida por Rawls em sua primeira obra, Uma Teoria da Justiça. Nela, o autor não nega os efeitos distributivos da saúde, reconhecendo que medidas eficazes de saúde pública podem influenciar as condições necessárias para a promoção dos objetivos dos indivíduos. No entanto, como são justas as desigualdades sociais e econômicas na sociedade por ele imaginada, esses efeitos são postos de lado (RAWLS, 2008).

Assim, a teoria rawlsiana, no estágio da posição original, não coloca a saúde enquanto problema de justiça distributiva. Ao contrário, pressupõe que, na sociedade bem-ordenada, todos os indivíduos são participantes plenos e ativos da sociedade: "todos têm necessidades físicas e capaci- 
dades psicológicas no âmbito da normalidade de modo que questões de cuidados médicos especiais e de capacidade não se apresentam." (RAWLS, 2008, p. 116).

Apesar dessa suposição, Rawls, em suas obras mais recentes, não desconsidera que as pessoas possam sofrer acidentes ou padecer de alguma doença, uma vez que tais fatos constituem infortúnios normais no curso da vida. Em Justiça como equidade, Rawls (2003, p. 78) sustenta que certo nível de desigualdade de perspectivas de vida dos cidadãos é necessário para que a sociedade seja bem planejada e efetivamente ordenada, visto que essas perspectivas são profundamente afetadas pelas seguintes contingências:

a) contingência social - a classe social de origem do indivíduo;

b) contingência natural - seus talentos naturais e as oportunidades que tem para desenvolver esses talentos em razão da classe social de origem;

c) contingência fortuita - sua boa ou má sorte ao longo da vida (como será afetado por doenças ou acidentes e por períodos de desemprego involuntário ou declínio econômico geral).

Além de serem influenciadas por essas contingências, as perspectivas de vida também são afetadas "pela maneira como a estrutura básica dispõe as desigualdades e usa essas contingências para cumprir certas metas sociais." (RAWLS, 2003, p. 78).

Assim, a estrutura básica não pode ignorar as desigualdades nas perspectivas de vida dos cidadãos decorrentes das contingências sociais, naturais e fortuitas, devendo instituir as regulamentações necessárias para preservar a justiça de fundo, sob pena de não levar "a sério a ideia de sociedade como um sistema equitativo de cooperação entre cidadãos livres e iguais." (RAWLS, 2003, p. 78-79).

Como se vê, em vez de desconsiderar os efeitos das questões de saúde sobre os planos de vida dos indivíduos, como faz em Uma Teoria da Justiça e em Justiça como equidade, Rawls atribuiu à estrutura básica o dever de estabelecer instituições que tratem sobre os problemas relacionados à saúde.

A regulação dessas questões não pode ser feita no estágio da posição original, ${ }^{4}$ já que nela os indivíduos, por estarem cobertos com o véu da ignorância, desconhecem as circunstâncias da sociedade, não podendo, assim, ter informações sobre as doenças existentes, bem como as limitações delas decorrentes e as necessidades das pessoas doentes.

Considerações sobre saúde também não podem ser feitas no estágio constitucional, pois, segundo a divisão de trabalho proposta por Rawls entre esses estágios, na fase constituinte as análises devem ser guiadas pelo primeiro princípio de justiça, de modo que, nesse estágio, são analisadas apenas as determinantes que se relacionam com o princípio da liberdade igual: a proteção

4 Rawls acredita que a especificação dos sistema de liberdades e direitos é feita por meio da aplicação dos princípios de justiça ao longo de quatro estágios: a posição original, o constitucional, o legislativo e o judicial. 
das liberdades fundamentais individuais, da liberdade de consciência e da liberdade de pensamento; e o estabelecimento de um processo político que como um todo seja um procedimento justo (RAWLS, 2008).

No terceiro estágio, o legislativo, entra em ação o segundo princípio de justiça, que visa determinar as políticas sociais e econômicas maximizadoras das expectativas de longo prazo dos menos favorecidos, em condições de igualdade equitativa de oportunidades. Dessa forma, "neste ponto, entra em jogo toda a gama de fatores sociais e econômicos de caráter geral" (RAWLS, 2008, p. 244), entre eles, os relacionados à saúde.

Já o quarto estágio (o judicial) destina-se à aplicação das normas a casos específicos por juízes e administradores. Nele, "não há mais limites ao conhecimento, pois já foi adotado o sistema completo de normas que se aplica aos indivíduos em virtude de suas características e circunstâncias." (RAWLS, 2008, p. 245).

Deve-se ressaltar que a transferência da preocupação com a saúde (e outros fatores sociais e econômicos) para o estágio legislativo tem por fim evitar o desvio da questão fundamental que Rawls pretende responder: qual concepção de justiça é mais apropriada para especificar os termos da cooperação social entre cidadãos concebidos como livres e iguais e como membros normais e plenamente cooperativos da sociedade ao longo de toda a vida? (RAWLS, 2011).

Assim, sendo necessárias maiores informações sobre as contingências sociais para se considerarem as questões de saúde, Rawls transfere as considerações sobre a saúde para os estágios posteriores, mais especificamente para o estágio legislativo, no qual, em razão de o véu da ignorância ser menos espesso, já é possível o conhecimento sobre os custos dos tratamentos e os recursos estatais que podem ser disponibilizados.

Assim, a ideia de acesso à saúde deve estar inserida no debate sobre justiça social e equidade (PEREIRA, 1990). O crescente aumento dos gastos com a saúde, principalmente em razão da incorporação de novas tecnologias (TRINDADE, 2008), tem contribuído para fomentar essa discussão. Entretanto, deve-se ressaltar que o acesso à saúde possui múltiplas dimensões que combinam fatores financeiros e não financeiros (SANCHEZ; CICONELLI, 2012).

Apesar da dificuldade de conceituar acesso à saúde, é possível destacar no interior da definição de Sanchez e Ciconelli (2012) quatro elementos principais, que cada vez mais se confundem com a definição de equidade em saúde: disponibilidade, aceitabilidade, capacidade de pagamento e informação. A reflexão converge para a compreensão de que o acesso e a equidade à saúde não podem estar circunscritos ao nível de atuação dos sistemas de saúde, mas atravessam ações intersetoriais das mais diversas áreas governamentais, em especial: as políticas sociais e econômicas, a melhor distribuição de renda, o fortalecimento da cidadania e melhores condições de educação e habitação (SANCHEZ; CICONELLI, 2012).

A título de comprovação da dificuldade de acesso aos tratamentos em leitos de UTINs, fez-se um levantamento de dados em dois setores estratégicos no Estado do Maranhão: Judicial e 
Executivo. Este estudo partiu de uma análise processual, ou seja, um levantamento de demandas em que o objeto principal da ação tenha sido o pedido de internação de neonascidos em UTINs. Além disso, também para efeitos de demonstração da dificuldade de acesso nessas internações, foi realizado um levantamento de número de leitos de UTINs públicas disponíveis no Estado do Maranhão, tanto os leitos estaduais quanto os leitos federais instalados e em funcionamento.

Em primeiro plano, realizou-se uma busca processual com o Tribunal de Justiça do Maranhão de demandas que tiveram por objeto a solicitação de internação em leitos de UTINs. Por questão de distribuição e organização judiciária, essas ações não tramitaram nas varas da Fazenda Pública, mas nas varas da Infância e Juventude. São Luís, capital do Estado, possui duas varas da Infância e Juventude, visto que apenas a primeira é responsável pelo julgamento desse tipo de ação.

Foi feito um levantamento manual das ações com solicitação de leitos de internação em UTINs no período de 2012 a 2013. O recorte histórico 2012 a 2013 justificou-se pela dificuldade de busca desses processos, que além de não digitalizados, estavam, por tratarem de menores, submetidos ao segredo de justiça. Foram encontrados sete processos judiciais sobre o tema. Sequencialmente, também foram disponibilizadas pela $1^{\text {a }}$ Vara da Infância e Juventude as cópias das sentenças dessas ações respectivas, suprimindo-se informações sobre os postulantes.

A segunda etapa constituiu-se na coleta de dados de UTINs públicas presentes no Estado do Maranhão. A Secretaria de Saúde (SES) informou que possui 117 leitos instalados de UTINs em hospitais públicos do Estado, sendo desse total 23 leitos no Complexo Hospitalar Materno Infantil do Maranhão Dr. Juvêncio Mattos e Benedito Leite; 38 (trinta e oito) leitos no Hospital e Maternidade Marly Sarney, todos localizados na Cidade de São Luís, capital do Estado; 13 leitos no Hospital Alexandre Mamede Trovão, localizado na Cidade de Coroatá, MA; e 43 no Hospital Regional Materno Infantil de Imperatriz, localizado na Cidade de Imperatriz, MA.

A Secretaria de Saúde informou, ainda, que não possui em seus registros a quantidade de leitos que estão em funcionamento. No mesmo sentido, a partir de pesquisa realizada no banco de dados do DATASUS, constatou-se a existência no Hospital Universitário Presidente Dutra (hospital federal, localizado na Cidade de São Luís, MA), de 38 leitos de UTINs tipo 1, e 38 leitos de UTINs tipo 2, em um total de 76 leitos de UTINs federais. A Superintendência do hospital informou que todos os leitos instalados nas dependências do hospital universitário estavam em pleno funcionamento. Em pesquisa nos bancos de dados do Ministério da Saúde e das Secretarias estaduais e municipais de saúde constatou-se que, com exceção dos municípios citados, nenhum outro possui esse tipo de leito especializado em seus hospitais.

Esses leitos abastecem uma população estimada em 6.850 .884 habitantes, de acordo com o censo realizado pelo IBGE no ano 2014 no Estado do Maranhão. O sistema DATASUS informa que a mortalidade infantil no Maranhão é altíssima, superior à média nacional (IBGE, 2009). Na faixa de zero a um ano, em 2008 no Brasil, a cada 1.000 nascidos vivos, a taxa de mortalidade era de 17,6, e no Maranhão, de 24,0 (IBGE, 2009), um dos piores índices registrados. 
Além disso, a taxa de mortalidade infantil por faixa etária de óbitos por causas evitáveis em menores de cinco anos, em 2012, foi de 984 óbitos em neonatos de zero a seis dias e de 204 de sete a 27 dias, totalizando 1.188 óbitos na faixa etária de acomodação de uma UTIN. O número de óbitos fetais em 2013 no Nordeste foi de aproximadamente 11.000 e no Maranhão de aproximadamente 2.000 (BARBEIRO et al., 2015). No Nordeste o número de óbitos neonatais apresentou uma discreta diminuição, entretanto, o Maranhão manteve a mesma proporção na taxa de óbitos fetais (BARBEIRO et al., 2015).

De acordo com dados do SUS, no ano 2013 o Maranhão registrou o terceiro maior índice de óbitos fetais e infantis no Nordeste, perdendo apenas para Pernambuco e Bahia. Até setembro de 2014 aconteceram 1.231 óbitos, entre os quais, quase 70\% ocorreram entre neonatos e neonatos tardios (BRASIL, 2014).

Entende-se mortalidade infantil como o risco de nascido vivo morrer antes de completar um ano de vida. Para Lourenço, Brunken e Luppi (2013), a mortalidade infantil é um indicador fundamental para a mensuração da saúde de uma população. Pesquisas (LORENÇO; BRUNKEN; LUPPI, 2013) indicam que a mortalidade infantil pode ser impactada por fatores genéticos, pela qualidade da assistência no pré-natal e no parto, e, notadamente, pelo acesso a serviços de saúde que disponibilizem infraestrutura e profissionais qualificados para o cuidado em UTINs.

Com o escopo de compreender o panorama do atendimento e da judicialização do acesso aos leitos de UTINs no Estado do Maranhão, realizou-se uma análise das normas infralegais sobre a temática e das demandas judiciais acessadas, no período de 2012 a 2013, conforme segue.

\section{Normas infralegais, judicialização e acesso a UTINs no Estado do Maranhão}

A ocasião do nascimento de uma criança é um momento único e que pode determinar o seu desenvolvimento e o seu crescimento saudável (BRASIL, 2012). Nesse instante em que podem acontecer muitas variáveis, também é possível surgir inevitavelmente a necessidade de uma internação em UTIN em razão da possibilidade de um tratamento específico e especializado (PEDROSA; SARINHO; ORDONHA, 2007).

Estudos indicam que o útero é considerado o local ideal para o crescimento e o desenvolvimento fetal, "[...] pois possui características distintas, como temperatura agradável e constante, maciez, aconchego, e os sons extrauterinos são filtrados e diminuídos." (REICHERT; LINS; COLLET, 2007). Quando ocorrem obstáculos à continuidade regular da gestação, apresenta-se a importância de uma UTI neonatal, unidade que possibilita uma experiência ao recém-nascido bastante parecida com aquela vivida no ambiente uterino.

A UTIN tem permitido a sobrevivência de neonatos que até pouco tempo não conseguiam sobreviver sem os cuidados necessários (ARAUJO et al., 2005). Porém, em que pese o reconhecimento dessa importância, contraditoriamente essa unidade que deveria primar pelo bem-estar do bebê 
em todos os seus aspectos "[...] é por excelência um ambiente nervoso, impessoal e até temeroso para aqueles que não estão adaptados às suas rotinas." (REICHERT; LINS; COLLET, 2007). Esse ambiente é cheio de luzes "[...] fortes e constantes, barulho, mudanças de temperatura, interrupção do ciclo do sono, visto que são necessárias repetidas avaliações e procedimentos, acarretando, muitas vezes, desconforto e dor." (REICHERT; LINS; COLLET, 2007).

Esse ambiente, embora considerado imprescindível pela tecnologia sofisticada que assegura a vida, é ainda muito invasivo pela forma agressiva das técnicas e procedimentos aos quais os bebês são submetidos. Essas ações, por vezes necessárias, "[...] podem transformar o profissional, tornando-o insensível, racional e desumano, evidenciando o empoderamento da ciência e da técnica sobre o homem." (SÁ NETO; RODRIGUES, 2010). Ainda assim, as UTINs têm garantido a sobrevida de milhares de crianças em todo o País.

As Unidades de Terapia Intensiva (UTIs), conforme estabelece a Portaria n. 3.432, de 12 de agosto de 1998, expedida pelo Ministério da Saúde, são acomodações hospitalares destinadas ao atendimento de pacientes graves ou de risco que dispõem de auxílio médico e de enfermagem continuado, "com equipamentos específicos próprios, recursos humanos especializados e, que tenham acesso a outras tecnologias destinadas a diagnóstico e terapêutica." (MINISTÉRIO DA SAÚDE, 1998).

Entretanto, essas unidades podem atender a grupos etários e específicos. No caso da UTI Especializada, os cuidados são voltados para pacientes atendidos por determinada especialidade ou pertencentes a um grupo especial de doenças, como, por exemplo, aquelas destinadas aos cardiopatas.

Quando se considera a idade dos pacientes, poderá ser classificada em UTI Adulto (destinada ao atendimento de pacientes maiores de 14 ou 18 anos), UTI Pediátrica (voltada a pacientes de 28 dias a 14 ou 18 anos) e, por fim, a unidade que foi o objetivo central do presente estudo, a UTI Neonatal (designada ao atendimento de pacientes de zero a 28 dias de vida).

A Portaria n. 3.432, de 12 de agosto de 1998, do Ministério da Saúde adverte, ainda, que todo hospital com capacidade igual ou superior a 100 leitos necessita de UTI correspondente a no mínimo $6 \%$ dos leitos totais e, que todo hospital especializado em atendimento de gestantes de alto risco deve dispor de leitos de tratamento intensivo adulto e neonatal.

As UTINs têm em seu quadro uma equipe formada por profissionais de diversas áreas. Além de esta ser altamente especializada, o hospital com instalações de UTI neonatal deve estar equipado e ter em disponibilidade todo um conjunto de laboratórios, equipamentos e serviços (OLIVEIRA et al., 2006).

O hospital deve contar, ainda, com acesso a estudo hemodinâmico; angiografia seletiva; endoscopia digestiva; fibrobroncoscopia e eletroencefalografia. A Portaria citada estabelece, também, que todos os materiais e equipamentos necessários e específicos que devem também estar presentes nas UTINs. Nesse sentido,

[...] a tecnologia não pode ser vista como algo concreto, mas como resultado de um trabalho que envolve um conjunto de ações com a finalidade de aumentar e 
melhorar o tratamento e o cuidado por meio da prática em saúde. Também se manifesta na forma de conhecimentos e habilidades associadas ao uso e à aplicação destes recursos dentro de um sistema governamental, organizacional e de pessoas integradas, com o objetivo de maximizar a eficiência e a racionalidade da tecnologia aplicada. (SÁ NETO; RODRIGUES, 2010, p. 375).

Um dos grandes obstáculos à instalação de novas UTINs é o custo; soma-se a esse fator um dos graves problemas do gerenciamento em saúde no Brasil, que é a qualidade da assistência à saúde, o que pode dificultar ainda mais a previsão de recursos materiais e a relação entre oferta de serviços e demandas de saúde. Nesse ínterim, a administração de recursos materiais dentro das casas de saúde tem recebido maior atenção, "[...] pois junto com os recursos humanos, os recursos financeiros formam a base de sustentação do hospital, sendo este último um de seus elementos principais." (LOPES; DYNIEWICZ; KALINOWSKI, 2010).

A Portaria n. 2.351, de 05 de outubro de 2011, alterou a Portaria n. 1.459, de 2011, e instituiu, no âmbito do Sistema Único de Saúde, a rede cegonha. Nesse documento existe a previsão de custos de instalação de um leito de UTIN. No anexo II a memória de cálculo de novos investimentos e custeios da rede cegonha está prevista da seguinte forma: "Ampliação de leitos de UTI neonatal e UTI adulto: R\$ 100.000,00/leito para aquisição de equipamentos e R \$20.000,00/leito para reforma."

Deve-se, no entanto, destacar que os programas sociais implementados no Brasil são, cada vez mais, marcados pela insuficiência, precariedade e descontinuidade, representando muito mais esforços meramente simbólicos do que efetivas políticas capazes de alterar as condições de vida das populações atendidas, até porque se registra profunda desarticulação entre as políticas sociais e as políticas macroeconômicas, reduzindo as primeiras a patamares meramente compensatórios, quando não assistencialistas e clientelistas (SILVA, 2007, p. 13).

No que diz respeito à cobertura de leitos de UTINs, Barbosa (2004) apresentou pelos menos cinco obstáculos que dificultam ou inviabilizam a prestação do serviço, quais sejam: falta de planejamento estratégico adequado; ausência de equidade na distribuição de leitos, com desigualdades nacionais e regionais; alto custo para instalação e manutenção do serviço, além da escassez de recursos humanos e materiais; acesso limitado e estrutura desigual, com qualidade dos serviços prestados extremamente variável, com a convivência de unidades altamente sofisticadas e outras sem a estrutura mínima necessária; e falta de informações confiáveis sobre o sistema e fiscalização precária do Poder Público.

Além disso, é preciso ressaltar que no Brasil inexiste um sistema legislativo específico sobre os parâmetros de cobertura assistencial em leitos de UTINs. Há apenas uma Portaria que fixa as diretrizes e os objetivos para a organização da atenção integral e humanizada ao recém-nascido grave ou potencialmente grave, e os critérios de classificação de leitos de Unidade Neonatal no âmbito do SUS, a Portaria n. 930, de 10 de maio de 2012, do Ministério da Saúde.

As Unidades Neonatais são divididas de acordo com as necessidades de cuidado em, respectivamente, Unidades de Terapia Intensiva Neonatal (UTINs) e Unidades de Cuidado Intermedi- 
ário Neonatal (UCINs) (artigo $6^{\circ}$ da Portaria n. 930). $\bigcirc$ artigo $7^{\circ}$ da referida Portaria determina que o número de leitos em UTINs atenderá ao parâmetro de necessidade populacional, visto que para cada mil nascidos vivos poderão ser contratados dois leitos de UTINs e três de UCINs.

De acordo com os dados do IBGE, o Maranhão teve 116.039 nascidos vivos em 2012 (nascimento por residência da mãe segundo o município), o que geraria uma necessidade de aproximadamente 232 leitos de UTINs no Estado (INSTITUTO DE PESQUISA ECONÔMICA APLICADA, 2010).

Partindo do pressuposto de que os 117 leitos de unidades neonatais no Estado são de UTINs, somados aos 38 leitos federais, ter-se-ia, na melhor das hipóteses, 155 leitos de UTINs no Estado, o que corresponde a aproximadamente $66 \%$ do percentual estabelecido pelo SUS. Esse percentual baixaria ainda mais se os dados fornecidos pelo Estado fizessem a diferenciação entre leitos de UTINs e UCINs.

A situação se torna mais grave diante da ausência de leitos de UCINs no Estado, uma vez que, de acordo com os dados recolhidos, são apenas 38 leitos, e todos inseridos no âmbito federal. Portanto, a quantidade de leitos de Unidade Neonatal no Estado é insuficiente para atender à demanda populacional. A seriedade dessa situação deságua diretamente na judicialização da saúde, em demandas que postulam acesso às UTINs.

O Tribunal de Justiça do Estado do Maranhão disponibilizou sete cópias de autos processuais judiciais entre 2012 e 2013, todas com pedidos de internação em leitos de UTINs. Do total, seis foram propostas pelo Ministério Público Estadual e apenas uma foi promovida por patrono particular.

A indicação do Ministério Público como principal representante dos autores vai de encontro, por um lado, às pesquisas desenvolvidas por Barata e Chieffi (2009), Marques e Dallari (2007) e Vieira e Zucchi (2007), na medida em que todos os demandantes são pessoas carentes, alertando para as deficiências e insuficiências do sistema de saúde local para responder satisfatoriamente às necessidades de saúde da população. Por outro lado, corrobora estudos desenvolvidos por Diniz, Machado e Penalva (2014) uma vez que estes afirmam a inexistência de evidências de que a judicialização seja um movimento das elites. Além disso, põe em relevo a atuação do Ministério Público nesse âmbito, instituição alçada à categoria de importante ator na reivindicação judicial e na garantia e ampliação de políticas públicas e direitos dos cidadãos após 1988.

Em todas as ações o polo passivo foi o Poder Público, visto que em cinco delas o Estado foi demandado com o Município de São Luís (capital do Estado). Do total, quatro foram Ações Civis Públicas, duas Ações Cautelares Inominadas e uma Obrigações de Fazer.

Aqui se deve ressaltar que o elemento motivador da judicialização foi a fragilidade da gestão pública estadual, o que põe em evidência que um dos principais obstáculos à garantia de acesso ao sistema de saúde é a falta de planejamento estratégico adequado por parte do Poder Público (BARBOSA, 2004). Além disso, segundo Lorenzetti et al. (2014), as fragilidades de gestão e o subfinancia- 
mento da saúde têm emergido, na última década, como problemas substanciais, e a judicialização da saúde, nesses casos, aparece como uma reação legítima à garantia do pleno exercício do direito à assistência individual terapêutica, elemento integrante do direito à saúde previsto na Constituição Federal de 1988 (PEPE et al., 2010).

Das sete ações demandadas, apenas em cinco foi arbitrada multa em caso de descumprimento. Entende-se que ausência de multa dificulta ou inviabiliza, por vezes, o escopo pretendido com a demanda judicial. Todos os processos fundamentaram sua argumentação no direito à vida (DINIZ; MACHADO; PENALVA, 2014) e na absoluta prioridade da infância, fazendo referência normativa apenas à Constituição Federal e ao Estatuto da Criança e do Adolescente. Essa questão destaca que as normas infralegais expedidas pelo Ministério da Saúde têm pouco ou nenhuma ascendência sobre as decisões judiciais. Em seis ações não havia demonstração de cumprimento da decisão liminar de internação, e em uma delas houve extinção do feito em razão de óbito do paciente. A falta de preocupação do Judiciário com a eficácia do cumprimento da sentença precisa ser refletida como elemento material integrante da própria decisão. Não raro, o paciente obtém a liminar, mas continua fora do sistema de atendimento e tratamento.

A análise constata que o Ministério Público como guardião da lei e titular do inquérito civil e das ações civis públicas, por vezes, perde a oportunidade de atuar coletivamente, na medida em que tem condições legais e instrumentais para exigir o cumprimento das normas infralegais expedidas pelo Ministério da Saúde. Constatou-se que não houve referência, nas ações judiciais analisadas, a qualquer instrumento normativo infralegal do Ministério da Saúde de orientação à quantidade e designação de leitos em UTINs no Estado. Também não houve referência sobre a necessidade de anuência do cumprimento da decisão, além disso, percebeu-se ausência de diálogo entre os membros do Poder Judiciário e do Executivo, bem como das três esferas federativas.

Deve-se destacar que, ainda que as decisões judiciais tenham sido positivas aos requerentes, uma vez que todas foram deferidas, elas em sua maioria não tiveram eficácia (MAZZA; MENDES, 2014), pois não há no processo qualquer comprovação do cumprimento tempestivo das decisões judiciais e, como o quantitativo de leitos disponíveis no Estado era insuficiente para atender à demanda, via de regra, não foram cumpridas no prazo determinado pelo juízo.

A partir dos dados coletados, verifica-se que a judicialização da saúde é importante instrumento na garantia dos direitos sociais (DELDUQUE, 2014), em especial para a população desprovida de recursos econômicos e de acesso à saúde suplementar. No entanto, esse fenômeno já demonstrou sua incapacidade quando da eficácia das políticas públicas (OLIVEIRA et al., 2015), considerando que as ordens judiciais, ainda que proferidas em regime de urgência, via de regra, tornaram-se meras folhas de papel, tendo em vista a inexistência de condições materiais e humanas que possibilitem sua execução, assim como a fragmentação, a desorganização e a falta de boa governança do sistema.

Para além da judicialização, prima-se pela construção de uma nova abordagem do direito à saúde (RAMOS, 2014) que atravesse a construção de um diálogo de paridade entre os Poderes Ju- 
diciário e Executivo e a sociedade civil (RAMOS; MADUREIRA; SENA, 2013), desencadeando uma reestruturação do Sistema Único de Saúde e da própria definição das prioridades em saúde para as próximas décadas no Estado do Maranhão e no Brasil.

\section{Conclusão}

Buscou-se analisar um problema extremamente relevante no cenário atual: a eficácia do acesso a leitos de UTINs. São notórias as grandes dificuldades que esse tema enfrenta para ser garantido. Os direitos sociais e o direito à saúde, em especial, dependem, em regra, de uma atividade prestacional para uma efetiva concretização, logo, necessitam de disponibilidade financeira e da distribuição orçamentária dos recursos públicos do Estado.

A sociedade é dinâmica e apresenta em suas características um grau elevado de desigualdade social. Assim, as condições de saúde refletem dimensões sociais de renda, moradia, saneamento básico e, nesse ponto, ao se vislumbrarem classes mais privilegiadas em suas plúrimas dimensões e as menos privilegiadas, verifica-se que estas últimas têm maiores chances de intercorrências na saúde, uma vez que se encontram desprovidas de direitos e serviços básicos na sociedade. Outro lado que pode ser registrado é o fato de que modificações nas características de oferta do sistema de saúde alteram diretamente as desigualdades sociais em longo prazo (RAMOS, 2014).

Nesse sentido, o aumento de demandas judiciais que buscam a concretização de direito à saúde se apresenta como redescoberta dos direitos e ampliação da consciência de cidadania. A judicialização da saúde expõe os limites e as possibilidades do referido setor e do próprio sistema de justiça. As demandas judiciais em âmbito sanitário estão relacionadas principalmente ao fornecimento de medicamentos, à realização de cirurgias e procedimentos, à incorporação de novas tecnologias no âmbito do Sistema Único de Saúde e de internação em leitos de UTIs.

No que diz respeito ao acesso a leitos de UTINs, um dos grandes obstáculos na solicitação de internação desse tipo de leito aos neonatais é o fator tempo. Os neonatos, quando precisam de UTI e não encontram vaga para a sua internação, não dispõem de tempo suficiente, após a negativa de internação, para promover uma demanda judicial e, se concedida, ter efetividade no cumprimento da sentença. Na maioria das vezes, acabam com sequelas ou em óbito.

A Portaria n. 930, de 10 de maio de 2012, estabelece o número de leitos em Unidades Neonatais que devem existir nos Estados, porém o que se observou foi um quantitativo bem inferior ao que ela determina. E o número ainda poderia ser menor, primeiro se o Estado tivesse em seus dados o número de leitos em funcionamento, uma vez que foi disponibilizada apenas a informação de leitos instalados, e segundo, se fosse separado o número de cada unidade de tratamento.

Além disso, como afirmado, a Sociedade Brasileira de Pediatria considera que o ideal seriam quatro leitos de UTINs para cada mil nascidos vivos, ao invés de dois como estabelece a Portaria (RAMOS; SOUSA; MADUREIRA, 2015). Porém, tem-se que adequar o real, do ideal e o possível. $\bigcirc$ 
ideal era que houvesse quatro leitos para cada mil nascidos vivos e se teriam aproximadamente 464 leitos. $\bigcirc$ possível é fazer cumprir o que determina a Portaria, somente assim se poderia incentivar os hospitais particulares a aumentarem e instalarem os leitos em UTINs nas suas casas de saúde. O resultado dessa deficiência é a crescente judicialização, porém não pode o Judiciário substituir o Legislativo, uma vez que não possui legitimidade democrática para tal feito.

Viu-se, por meio de dados quantitativos e da análise de decisões judiciais que, em sua maioria, não há eficácia na decisão que concede leitos em UTINs, primeiro porque apesar de as decisões serem pelo deferimento dessas decisões, não existem leitos suficientes para a garantia dessa internação, e a ordem não tem como ser cumprida, salvo raras circunstâncias.

Torna-se urgente a instalação de um núcleo de mediação não governamental que aglutine a participação popular e todas as esferas de poder (RAMOS; MADUREIRA; SENA, 2014), com o escopo de encontrar a melhor solução. A estruturação de um ente dessa natureza terá legitimidade para evitar o manuseio excessivo de processos judiciais, exercerá o papel intercessor de interesses e demandas, estabelecerá prioridades sanitárias/jurisdicionais e atuará de forma equilibrada entre as esferas federativas e de governabilidade.

Além disso, o Poder Legislativo precisa atuar na elaboração de um sistema normativo que permita a destinação equitativa dos serviços e insumos de saúde, em especial do quantitativo de leitos em unidades neonatais, bem como de um instrumental que garanta a ampliação e a qualificação contínua dos recursos humanos vinculados ao sistema; de outra ordem, o Poder Executivo deve cumprir essa arquitetura normativa, garantindo à população a efetividade da promessa constitucional de saúde universal e integral.

\section{Referências}

AMARAL, Gustavo. Direito, escassez e escolha: em busca de critérios jurídicos para lidar com a escassez de recursos e as decisões trágicas. Rio de Janeiro: Renovar, 2001.

AÑóN, Carlos Lena. Salud, justicia, derechos. México: Dyknson, 2009.

ARAUJO, Breno Fauth de et al. Estudo da mortalidade de recém-nascidos internados na UTI neonatal do Hospital Geral de Caxias do Sul, Rio Grande do Sul. Rev. Bras. Saúde Mater. Infant., Recife, v. 5, n. 4, p. 463-469, dez. 2005. Disponível em: <http://www.scielo.br/scielo.php? script=sci_arttext\&pid=S1519-38292005000400010\&lng=pt\&nrm=iso $>$. Acesso em: 11 set. 2016.

ASSIS, Marluce Maria Araujo; JESUS, Washington Luiz Abreu de. Acesso aos serviços de saúde: abordagens, conceitos, políticas e modelos de análise. Ciência \& Saúde Coletiva, v. 17, n. 11, p. 28652875, 2012. Disponível em: <http://www.scielo.br/pdf/csc/v17n11/v17n11a02.pdf>. Acesso em: 14 set. 2015.

BARATA, R.; CHIEFFI, A. L. Judicialização da política pública de assistência farmacêutica e equidade, Cad. Saúde Pública, Rio de Janeiro, v. 25, n. 8, p. 1839-1849, ago. 2009. 
BARBEIRO, Fernanda Morena dos Santos et al. Óbitos fetais no Brasil: revisão sistemática. Rev. Saúde., Rio de Janeiro, v. 49, n. 22, 2015. Disponível em: <http://www.scielo.br/pdf/rsp/v49/pt_ 0034-8910-rsp-0034-89102015049005568.pdf>. Acesso em: 13 mar. 2016.

BARBOSA, Arnaldo Prata. Terapia intensiva neonatal e pediátrica no Brasil: o ideal, o real e o possível. J. Pediatr. (Rio J.), Porto Alegre, v. 80, n. 6, p. 437-438, dez. 2004. Disponível em: <http://www. scielo.br/scielo.php? script $=$ sci_arttext\&pid $=S 0021-75572004000800002 \& \operatorname{lng}=$ en $\& n r m=i s o>$. Acesso em: 13 set. 2016.

BRASIL. Constituição da República Federativa do Brasil. Brasília, DF: Senado Federal, 2014.

DALLARI, Gandolfi Sueli. Poderes Republicanos e a defesa do direito à saúde. Evolução da proteção do direito à saúde nas constituições do Brasil. In: ALVES, Sandra Mara Campos; DELDUQUE, Maria Célia; DINO NETO, Nicolau. Direito sanitário em perspectiva. Brasília, DF: ESMPU: FIOCRUZ, 2013.

DELDUQUE, Mari Célia. A construção do direito à saúde no Brasil rumo ao sistema único de saúde. In.: MARTINI, Sandra Regina; BILANCIA, Francesco. O direito à saúde na União Europeia e no Mercosul. Porto Alegre: Livraria do Advogado, 2014.

DINIZ, Debora; MACHADO, Teresa Robichez de Carvalho; PENALVA, Janaina. A judicialização da saúde no Distrito Federal, Brasil. Ciênc. Saúde Coletiva, Rio de Janeiro, v. 19, n. 2, p. 591-598, fev. 2014. Disponível em: <http://www.scielo.br/scielo.php?script=sci_arttext\&pi$\mathrm{d}=\mathrm{S} 1413-81232014000200591 \& \operatorname{lng}=\mathrm{en} \& \mathrm{nrm}=\mathrm{iso}>$. Acesso em: 13 set. 2016.

DONABEDIAN, Avedis. An introduction to quality assurance in health care. New York: Oxford University Press, 2002.

IBGE. Indicadores sociodemográficos e de saúde no Brasil. Rio de Janeiro, 2009. Disponível em: <http://www.ibge.gov.br/english/estatistica/populacao/indic_sociosaude/2009/indicsaude.pdf>. Acesso em: 17 mar. 2014.

INSTITUTO DE PESQUISA ECONÔMICA APLICADA. Atlas da vulnerabilidade social nos municípios brasileiros. Brasília, DF, 2015.

LOPES, Lauren Auer; DYNIEWICZ, Ana Maria; KALINOWSKI, Luísa Canestraro. Gerenciamento de materiais e custos hospitalares em UTI neonatal. Cogitare Enferm., v. 15, n. 2, p. 278-285, 2010. Disponível em: <http://ojs.c3sl.ufpr.br/ojs/index.php/cogitare/article/view/17862>. Acesso em: 10 dez. 2015.

LORENZETTI, Jorge et al. Gestão em saúde no Brasil: diálogo com gestores públicos e privados. Texto contexto - enferm., v. 23, n. 2, p. 417-425. 2014. Disponível em: <http://dx.doi. org/10.15900104-07072014000290013>. Acesso em: 17 mar. 2014.

MACHADO, Cristiani Vieira. O papel federal no sistema de saúde brasileiro. In: FUNDAÇÃO OSWALDO CRUZ. A saúde no Brasil em 2030 - prospecção estratégica do sistema de saúde brasileiro: organização e gestão do sistema de saúde [online]. Rio de Janeiro: Fiocruz: Ipea: Ministério da Saúde: Secretaria de Assuntos Estratégicos da Presidência da República, 2013. p. 35-70. Disponível em: <http://books.scielo.org/id/98kjw/pdf/noronha-9788581100173-04.pdf>. Acesso em: 17 ago. 2016. 
MARIO, Camila Gonçalves de. Saúde justa: uma concepção liberal-igualitária. In: ENCONTRO DA ABCP, 9., Brasília, DF, 2014. Anais... Brasília, DF, 2014. Disponível em: <http://www.encontroabcp2014.cienciapolitica.org.br/resources/anais/14/1403712316_ARQUIVO_ArtigoABCPSaudeliberaligualitaria.pdf >. Acesso em: 10 dez. 2014.

MARQUES, Silvia Badim; DALLARI, Sueli Gandolfi. Garantia do direito social à assistência farmacêutica no Estado de São Paulo. Brasil. Rev. Saúde Pública, v. 41, n. 1, p. 101-107, 2007.

MAZZA, Fábio Ferreira; MENDES, Áquilas Nogueira. Decisões judiciais e orçamento: um olhar sobre a saúde pública. R. Dir. Sanit., São Paulo, v. 14, n. 3, p. 42-65, fev. 2014. Disponível em: <http://www.revistas.usp.br/rdisan/article/view/75519/79077>. Acesso em: 12 set. 2016.

MINISTÉRIO DA SAÚDE. Portaria n. 1.459, de 24 de junho de 2011. Institui, no âmbito do Sistema Único de Saúde - SUS - a Rede Cegonha. Brasília, DF, 24 jun. 2011.

MINISTÉRIO DA SAÚDE. Portaria n. 2.351, de 05 de outubro de 2011. Altera a Portaria n 1.459/ GM/MS, de 24 de junho de 2011, que institui, no âmbito do Sistema Único de Saúde (SUS), a Rede Cegonha. Brasília, DF, 05 ou. 2011.

MINISTÉRIO DA SAÚDE. Portaria n. 3.432/MS/GM, de 12 de agosto de 1998. Estabelece critérios de classificação para as Unidades de Tratamento Intensivo - UTI. Disponível em: <http://bvsms. saude.gov.br/bvs/saudelegis/gm/1998/prt3432_12_08_1998.html>. Acesso em: 19 mar. 2016.

MINISTÉRIO DA SAÚDE. Portaria n. 930, de 10 de maio de 2012. Define as diretrizes e objetivos para a organização da atenção integral e humanizada ao recém-nascido grave ou potencialmente grave e os critérios de classificação e habilitação de leitos de Unidade Neonatal no âmbito do Sistema Único de Saúde (SUS). Disponível em: <http://bvsms.saude.gov.br/bvs/saudelegis/gm/2012/ prt0930_10_05_2012.html>. Acesso em: 10 abr. 2016.

MOIMAZ, Suzely Adas Saliba et al. Satisfação e percepção do usuário do SUS sobre o serviço público de saúde. Physis, Rio de Janeiro, v. 20, n. 4, p. 1419-1440, dez. 2010. Disponível em: < http:// www.scielo.br/scielo.php?script $=$ sci_arttext\&pid $=$ S0103-73312010000400019\&lng $=$ en \&nrm $=i-$ so >. Acesso em: 14 set. 2016.

OLIVEIRA, Beatriz Rosana Gonçalves de et al. O processo de trabalho da equipe de enfermagem na UTI Neonatal e o cuidar humanizado. Texto contexto - enferm., v. 15, p. 105-113, 2006. Edição Especial. Disponível em: <http://dx.doi.org/10.1590/S0104-07072006000500012>. Acesso em: 01 jul. 2016.

OLIVEIRA, Maria dos Remédios Mendes et al. Judicialização da saúde: para onde caminham as produções científicas? Saúde Debate, Rio de Janeiro, v. 39, n. 105, p. 525-535, abr./jun. 2015. Disponível em: <http://www.scielo.br/pdf/sdeb/v39n105/0103-1104-sdeb-39-105-00525.pdf>. Acesso em: 10 dez. 2014.

OLIVEIRA, Renata Camilo de. A Direito à saúde: considerações sobre sua judicialização à luz da decisão do STF no STA-AGR n. 175 e da Lei n. 12.401/2011. Revista da Faculdade de Direito da Universidade São Judas Tadeu. A efetividade dos direitos fundamentais, n. 3, jan./jun. 2015. Disponível em: <http://www.usjt.br/revistadireito/numero-3/3-renata-camilo-oliveira.pdf>. Acesso em: 14 set. 2016. 
PEDROSA, Linda Délia C. O.; SARINHO, Silvia W.; ORDONHA, Manoelina R. Análise da qualidade da informação sobre causa básica de óbitos neonatais registrados no Sistema de Informações sobre Mortalidade: um estudo para Maceió, Alagoas, Brasil, 2001-2002. Cad. Saúde Pública, Rio de Janeiro, v. 23, n. 10, p. 2385-2395, out. 2007. Disponível em: <http://www.scielo.br/scielo. php? script $=$ sci_arttext\&pid $=$ S0102-311X2007001000013\&lng $=$ en \&nrm $=$ iso $>$. Acesso em: 14 set. 2016.

PEPE, Vera Lúcia Edais et al. A judicialização da saúde e os novos desafios da gestão da assistência farmacêutica. Ciênc. saúde coletiva, v. 15, n. 5, p. 2405-2414, 2010. Disponível em: <http://dx.doi. org/10.1590/S1413-81232010000500015>. Acesso em: 10 mar. 2016.

PEREIRA, João. Justiça social no domínio da saúde. Cad. Saúde Pública, Rio de Janeiro, v. 6, n. 4, p. 400-421, dez. 1990. Disponível em: <http://www.scielo.br/scielo.php?script=sci_arttext\&pi$\mathrm{d}=\mathrm{S} 0102-311 \mathrm{X} 1990000400004 \& \operatorname{lng}=\mathrm{en} \& \mathrm{nrm}=\mathrm{iso}>$. Acesso em: 14 set. 2016.

PINHEIRO, Roseni; SENSI, Felipe Dutra. Desafios e estratégias de efetivação do direito à saúde. Physis, v. 20, n. 1, p. 15-17, 2010. Disponível em: <http://www.scielo.br/scielo.php?script=sci_arttext\&pid=S0103-73312010000100002 >. Acesso em: 12 ago. 2016.

RAMOS, Edith Maria Barbosa; MADUREIRA, Amanda Silva; SENA, Jaqueline Prazeres de. Mediação de saúde: desafios e perspectivas. In: CHAI, Cassius Guimarães; SOUSA, Maria do Socorro Almeida de (Org.). Mediação e direitos sociais indisponíveis: trabalho, saúde, educação e meio ambiente. São Luís: Procuradoria Geral de Justiça do Estado do Maranhão: Jornal da Justiça: Cultura, Direito e Sociedade, 2014.

RAMOS, Edith Maria Barbosa; MADUREIRA, Amanda Silva; SENA, Jaqueline Prazeres de. O processo de redemocratização e o novo padrão de proteção do direito à saúde no Brasil. Cadernos Ibero-Americanos de Direito Sanitário, Brasília, DF, v. 2, n. 2, p. 51-67, jul./dez. 2013.

RAMOS, Edith Maria Barbosa Ramos; SOUSA, Lidia Cunha Schramm de; MADUREIRA, Amanda. Direito à saúde: a judicialização para garantia de leitos em UTI neonatal em São Luís do Maranhão. Bogotá: UNAL, 2015. Disponível em <http://pensamiento.unal.edu.co/fileadmin/recursos/ focos/focosalud/docs/trabajos_cientificos/ensayos_cortos/iberoamericano_judicializacao_uti_neonatal.pdf >. Acesso em: 13 mar. 2015.

RAMOS, Edith Maria Barbosa. Universalidade do direito à saúde. São Luís: EDUFMA, 2014.

RAWLS, John. Justiça como equidade: uma reformulação. Tradução Claudia Berliner. São Paulo: Martins Fontes, 2003.

RAWLS, John. O liberalismo político. Tradução Álvaro de Vita. São Paulo: Martins Fontes, 2011.

RAWLS, John. Uma Teoria da Justiça. 3. ed. São Paulo: Martins Fontes, 2008.

REICHERT, Altamira Pereira da Silva; LINS, Rilávia Nayara Paiva; COLLET, Neusa. Humanização do Cuidado da UTI Neonatal. Revista Eletrônica de Enfermagem, v. 9, n. 1, p. 200-213, 2007. Disponível em: <http://www.fen.ufg.br/revista/v9/n1/v9n1a16.htm>. Acesso em: 22 nov. 2014.

SANCHEZ, Raquel Maia; CICONELLI, Rozana Mesquita. Conceitos de acesso à saúde. Rev. Panam. Salud Publica, v. 31, n. 3, p. 260-268, 2012. 
SÁ NETO, José Antonio de; RODRIGUES, Benedita Maria Rêgo Deusdará. Tecnologia como fundamento do cuidar em Neonatologia. Texto Contexto Enferm., Florianópolis, v. 19, n. 2, p. 372-377, abr./jun. 2010.

TRINDADE, Evelinda. A incorporação de novas tecnologias nos serviços de saúde: o desafio da análise dos fatores em jogo. Cad. Saúde Pública, Rio de Janeiro, v. 24, n. 5, p. 951-964, maio 2008. Disponível em: <http://www.scielo.br/pdf/csp/v24n5/02.pdf>. Acesso em: 02 dez. 2014.

VENTURA, Miriam et al. Judicialização da saúde, acesso à justiça e a efetividade do direito à saúde. Physis, v. 20, n. 1, p. 77-100, 2010. Disponível em: <http://www.scielo.br/scielo.php?script=sci_arttext\&pid=S0103-73312010000100006 >. Acesso em: 02 dez. 2014.

VIEIRA, Fabiola Sulpino; ZUCCHI, Paola. Distorções causadas pelas ações judiciais à política de medicamentos no Brasil. Rev. Saúde Pública, v. 41, n. 2, p. 214-222, 2007.

VITA, Álvaro de. A justiça igualitária e seus críticos. 2. ed. São Paulo: Martins Fontes, 2007.

Data da submissão: 24 de setembro de 2016 Avaliado em: 06 de abril de 2017 (AVALIADOR A) Avaliado em: 19 de abril de 2017 (AVALIADOR B) Aceito em: 08 de agosto de 2017 